\title{
Sociolinguistic Influence in the Use of English as a Second Language (ESL) Classroom: Seeing from OGO's Perspective
}

\author{
Lana Hasanah ${ }^{1}$, Siska Pradina ${ }^{2}$, Almira Hadita ${ }^{3}$, and Wella Cisilya Putri ${ }^{4}$ \\ ${ }_{1,2,3}$ State High School 3, Pekanbaru, Indonesia \\ ${ }^{4}$ State High School 7, Pekanbaru, Indonesia \\ lanahasanah12@gmail.com
}

\author{
ARTICLE HISTORY \\ Received : 3 May 2019 \\ Revised : 26 May 2019 \\ Accepted : 27 May 2019

KEYWORDS
Sociolinguistics
Perspective
Parents'Occupation
Article Review
English as a Second Language (ESL)

\begin{abstract}
This paper aims to provide a brief overview and review of the research conducted by Ofodu Graceful Onovughe (OGO) under the title Sociolinguistic Input and English as Second Language Classrooms published by the Canadian Center for Science and Education. This article also intended to provide a brief review of the sociolinguistic influences of the use of the second most significant language in the class. Using qualitative descriptive analysis, this study managed to see that OGO's research used survey within a population of all middle school students in the Akure Ondo Regional Government, Nigeria ( $\mathrm{N}=240$ students). Of the five existing hypotheses, the findings revealed that parents' occupation is a significant sociolinguistic influence on the use of English among middle school students, followed by gender, age, religion, and classes. This current paper evaluated how OGO's research is represented in his article. Results reveal the strengeths, weaknesses, and the flaws of the article.
\end{abstract}

\section{Introduction}

Ofodu Graceful Onovughe (henceforth: OGO) starts his 2012 article introduction by mentioning that Nigeria is a federal republic in West Africa, bordering Niger in the north, Chad in the northeast, Cameroon in the east, and Benin in the west. Nigeria is a place of language in all social structures that cannot be covered up. In the 2004 national policy the Nigerian Federal Government on education states that in appreciating language places as a means of promoting social interaction, national cohesion and preserving culture, every child must learn the language of the closest environment and one of three languages in Nigeria, besides English and France which is recognized as the second official language (Ofodu, 2009). This shows that students are burdened with many advantages of language which they must indirectly master.

Then, he continues in giving an explanation regarding language is an arbitrary sound-symbol system, which is used by all people or community members to cooperate, interact, and identify themselves in the form of good conversations, good behaviour, and good manners (Ofodu \& Adeniyi, 2008). What is meant by arbitrary language OGU mentioned "as the nature of sound, manuka or there is no logical relationship between the word which is used as a symbol or sign with what it symbolizes". For example, like a yellow flag, in yellow the flag is a yellow flag, while arbitrarily the yellow flag is a symbol of grief or death. Descriptive studies of the influence of each and all aspects of society, including cultural norms, expectations, and contexts, on the way language, is used are called sociolinguistics. And sociolinguistics is very influential in the use of English as a second language in the classroom. This is also the overall effect of society on language use. Ethnicity, religion, status, gender, education level, and age are different varieties of languages.

When it comes to language, humans have learned it from their birth. That starts from learning mother tongue, which is a natural and usual thing, but it's different from learning a second language or a foreign language. Briefly Littlewood (1984) distinguishes these two terms. A 'second' language has social functions within the community where it is learned (e.g., as a lingua franca or as the language of another social group), whereas a 'foreign' language is learned primarily for contact outside of one's community" (Sari, Putri, Herdi, \& Hamuddin, 2018). Quirk (1972) also argues that the second language is "a language is necessary for certain official, social, commercial or educational activities within their own country," whereas foreign languages is "a language used for communication across frontier or with others who are not from their country." The second language referred to here is a foreign language that is generally studied by students in a formal school or other similar educational institutions.

Then he continues to explain the position of English by mentioning, "Nowadays, language is something important and very much needed, especially for English. With learning English, a person can talk to other people from different countries due to the fact that English has been recognized as an international language used by people in the world. It is impossible if the Indonesian people meet Japanese people and they speak their language. That is 
certainly impossible, precisely what will happen, not the occurrence of good communication because of each other by understanding the language used. Well, English is the solution to overcome this. Which is means for promoting social interaction, national cohesion, and preserving culture are the contents of national policies on education proposed by the Nigerian Federal Government. This is what makes all children have to learn the language in their immediate environment. So students become burdened with the demands of many languages to learn.

English is the most widely spoken language in the world. As is known, English has become the second official language in several countries such as Singapore, New Zealand, etc. But for Britain and the United States, which are the two main Qibla countries, did not make English the official language law, but only in public recognition. English is an important factor in national unity. This makes people expect students at all levels to speak English well because English is also a mandatory requirement that must be fulfilled by all students before being accepted at the university. Also, the world of work today also prioritizes English as its priority. That's why English has become a language that determines student progress that can be done to obtain higher education and prestigious work. Therefore English has the advantage of all languages in the country this present study believe his main message that can be found in the article.

Somehow, when it refers to sociolinguistics, OGO mentioned in the next step of his explanation that the branch of linguistics that examines the relationship between language and its people. This science is a contextual study of variations in the use of community language in natural communication. The term sociolinguistics itself has been used by Haver C. Currie in an article published in 1952, the title of which is "A Projection of Sociolinguistics: The Relationship of Speech to Social Status" which contains problems related to the variety of languages a person has social status in society (Currie, 1980). Different groups of professions or positions in society tend to use a variety of different languages, and Sociolinguistics is the branch of linguistics that studies the social factors that play a role in the use of language and which play a role in the association (Booij, 2013).

The sociolinguistic background of a child influences the use of children's language in their daily lives-likewise, children's understanding of English in the classroom and the school environment. For example, a child from a high social class whose parents often use English to interact does not have a problem in using English as a second language in the classroom compared to children from low social classes whose parents are rarely or never using English in interacting makes using English as a second language in the classroom the biggest problem for the child, because the child has never or rarely heard the foreign language in his family environment.
Family is the first learning for a child, they learned words from them. This makes children feel difficult and unpleasant speaking English in class situations during the teaching-learning process. Family is an essential thing that is very important and influential for the development of English linguistics in students. Social stratification and social mobility of parents is very helpful to encourage or inhibit the communication skills and classes of student students, especially in the teaching and learning process in schools. The child's ability to use the language in class cannot be separated from the background of the language he has because the family is the first agent to socialize the language to children.

The child's socio-economic background also influences the learning process for them. This is evidenced that children from low socio-economics do not have the same access to learning as children from high socio-economic backgrounds. Children from high socio-economics have complete learning facilities at homes such as computers, televisions, gadgets, and other technologies that can help them in the learning process. This also makes high socioeconomic children smarter than children with low socioeconomic.

Age is also a factor in the use of the second language; research has revealed that age is an important factor in language use. Because the sooner a child starts learning a second language the better. Also, this can be proven that children have fast to capture the power and strong memories compared to parents due to age factors.

The place of gender in language learning as a second language cannot be ignored either because the research has supported the female students primarily use systems based on memorizing words and associations between them, while male students rely more on systems that govern language rules (Melville, 2006).

Religion is also a factor in L2 learning because it is an integral part of the learners' identity. Many school-age children sometimes encounter blocks during their education because they often adopt the western culture to the point that they can even forgot their mother tongue.

The most interesting part this study seen from OGU's introduction is when he mentioned "There are times when you also need to be able to understand the difference between British and American so that you don't get confused if you encounter these differences. Because between English and American have different accents, therefore, the importance of learning English in our lives is very useful as well as in the world of education". OGO's 'hook' is his smooth delivery of ideas to the audience. OGU mentioned that his study was conducted "to claim the influence of sociolinguist, which had the most significant influence in the use of English as a second language in the classroom with several hypotheses, namely the work of parents, gender, students' social class, ages, and religion" which this study sees as its main purpose in his article. 


\section{Method}

This article review uses a qualitative approach to explain articles entitled "Sociolinguistics Inputs and English as Second Language Classrooms" Published by Canadian Center of Science and Education which consists of 7 pages and is reinforced with 26 references in Vol. 5 No. 8; 2012 in Journal of English Language Teaching.

In this review-based article written by Ofodu Graceful Onovughe, from the Institute of Education, the Faculty of Education, Ekiti State University, revealed the existence of 5 hypotheses, namely the work of parents, gender, and social class of students, age, and also religion in vol. Five no.8. The data in this article was taken from schools in Nigeria with a sample of 240 high school students selected from 6 schools randomly.

This review-based study aims to obtain data on the most significant effects of the five hypotheses in Nigeria. This article also tries to see the strengths and weaknesses of the research with the aim of contributing ideas to academia. The findings of this study will also provide an overview of whether the article "Sociolinguistics Inputs and English as Second Language Classrooms" published by Canadian Center of Science and Education written by Ofodu Graceful Onovughe can be replicated in the same field or merely as a reference reading in the field sociolinguistics.

\section{Results}

\subsection{Strengths}

This journal article has various advantages. Namely, the thesis statement is clear and the author used words that are commonly used so that readers can more easily understand the contents of the journal. The material outlined in this article is very good and interesting, besides language that is easy to understand, the opinions expressed are also reinforced by experts. These can be seen in the pages 159160.

The title is synchronized well with the abstract (p. 157), which is written as a perfect summary of the entire article. The abstract includes the overall info in the article very well so that when the reader does not want to read the entire article, by reading the abstract itself the reader can understand the entire contents of the article. That is what is called a good abstract.

This article contains 26 references (p. 162-163), this is very good because of the more references used by the author, the more weight the article will be made. But unfortunately, the author does not write the website which is the main topic in this article so readers are troubled to explore further about it. Besides having a lot of good references and abstracts, this article also uses a language that is easily understood by the reader; the sentence is also not complicated so that it becomes one of the attractions for the reader. Besides that, the author also does not forget to include the expert name in each statement (p. 159), and this will also make the readers more confident about the statement.

\subsection{Weaknesses}

Judging from the title, this article has the title "Sociolinguistic Inputs and English as Second Language". This title is a bit confusing because the word "Sociolinguistic Inputs" if interpreted as a sociolinguistic input here is not reflected in what is meant (p. 157). This research articles must be clear in their purpose rather than relying on the intelligence of a fast reader.

The keywords in this article are available, except that they are less synchronous with the content because in this article there are five hypotheses that become keywords, namely parents 'work, gender, students' social class, age, and also a religion (p. 157). However, the keyword only mentions three hypotheses and does not mention religion and gender, even though the two are also important discussions in this article. And also 'input' which is one of the keywords here, it is very rare to see the word in this article, if it has become a keyword, it will often appear automatically.

This journal is quite clear the coherent writing pattern so that the reader is not confused. But unfortunately, the word selection is sometimes still ambiguous which results in different reasoning from each reader. This happens to the keyword 'age' and 'class levels' (p. 157). After reading it in its entirety, this article does not reveal what its exact age is, but only says 'age', it should be better to mention the specific age, so that readers become aware and more confident with the articles they read. Then the problem of 'class level', not all readers can immediately guess or think that the class level intended in this article is a social class of students, maybe there is one reader who thinks that the class level in question is class 1,2 , or 3 . This will also lead to ambiguity or misperception when the reader does not read the entire article and is only based on the abstract.

The first three pages are taken by the author to explain the introduction (p. 157-159). In this section, the information conveyed is quite complete but rather confusing because, in the introduction, there is another hypothesis that is expressed namely the notion of neurophysiology (p. 159). And the hypothesis is only in the introduction, but it doesn't matter, because this introduction is supported by the opinions of experts who strengthen it.

\subsection{Flaws}

This review-based article looks at the striking problems contained in the article entitled "Sociolinguistics Inputs and English as Second Language Classrooms" Published by Canadian Center of Science and Education which consists of 7 pages and is reinforced with 26 references in Vol. 5 No. 8; 2012 in Journal of English Language Teaching written by Ofodu Graceful Onovughe is how this research in pouring data in the result of hypothesis contained in pages 161-162. 
This study also found that the article contained glaring obstacles for readability. Particularly in the table figure, there are many abbreviations written such as ' $\mathrm{N}$ ' ' $\mathrm{SS}$ ' ' $\mathrm{DF}$ ' 'Ms' 'SD' Df 'Fcal' Ftable 'and many more. This should be avoided, because as a an author whose work is aimed for readership, there should be clear explanations for the codes that are used to make it easier for readers to understand the article and readers can also analyze the data. Even though this study managed to get the results of the research, it should be evaluated because not everyone can immediately understand the abbreviations authors make.

\section{Discussion}

In this review-based article, the authors reveal the existence of 5 hypotheses that have become sociolinguistic influences in using English as a second language in the classroom. These hypotheses include the work of parents, gender, students' social class, age, and also religion found on vol.5 no.8. In this case, the authors conducted a study to find out what was the most significant effect of using English as a second language in the classroom. The study was conducted with an adoption survey research design, in which the study population consisted of all secondary school students in the Ondo District Akure Regional Government. The sample from this study amounted to 240 students in the middle school class who were randomly selected from 6 secondary schools. The author chooses a high school class because students in high school have internalized the basics of English for the most part. The author provides a questionnaire for data collection and this relates to the demographic and sociolinguistic background of students.

The findings have revealed that parental work has input that will have a significant effect on students' use of English in the classroom. This shows that parents who are highly educated or can be categorized as parents whose middleclass economic life is above the possibility of using English as the language of everyday conversation at home since society is a microcosm of the big world, the effect will be clearly visible on the performance of their children because children are a reflection of parents.

Parents must take advantage of the findings of the results of this study talking and interact more frequently with students. Parents whose middle and upper economies are certainly able to meet their children's needs in improving their English skills. They have wide enough access to buy all educational materials such as televisions, computers, gadgets, and other technologies that can support students in the process of learning their language (Adeyemi \& Kalane, 2011).

This parental action translated into adequate use in the classroom. This finding supports the view of Bamisaye (2006) who says that the middle class shows complex linguistic codes, facilitates verbal development of subjective intentions and sensitivity to the implications of separateness and differences, provide complex conceptual hierarchies for finite codes of lower working classes distinguished by rigidity the syntax. The sociolinguistic background is family. Because it is in the family that students first get learning.

Furthermore, OGU sees that it is very important for children to always be able to learn and make great progress whether in language acquisition and development. It was also revealed that gender and the use of English by students did not have a strong relationship. The implication is that English students both men and women have the same opportunity to learn and get language tools. Both male and female students must try and be encouraged to use English at home and in the classroom, this, of course, must begin with itself.

Students' class, religion, and age were also revealed to have no significant effect on students' use of English in high school classrooms. Although there are studies that reveal that age is an important factor in language learning, language acquisition here depends on several hypotheses. Religion is a major factor in education. Sometimes many school children lose education because of the belief that western culture will culminate in learning a foreign language. Because psychologically, children's language mastery is not only influenced by their ability to reason and involvement in intellectual activities, but also motivation and effective factors. And children are more motivated to learn first and second languages than parents because this can be influenced by age factors.

Among the findings, it was also revealed that the age of students did not have a significant impact on the use of English in middle school students. One possible reason for this result can be seen in the fact that middle school students are no longer young. This supports the findings of Matsuoka \& Smith (2008). This research shows the fact that religion has nothing to do with language acquisition and learning because religion is a major factor in education. Religion is a tool of peace, stability, and security. In this case, parents must give them the freedom to learn whatever language they choose to learn. For the teaching and learning process, there is no element of compulsion so the lessons are also easier to accept.

\section{Conclusion}

It can be concluded from the findings of this study that the failure of a student in English between high school students is not due to gender, age, religion, age or anything, but because these failures occur because of other factors such as 'parents of students' in terms of work and their socio-economic background. Therefore, it is very important for all parents to help their environment by providing learning materials, time and other resources that can help their children's language skills in learning English. 
It is recommended that parents and all people who care about children's education should give all the best and adequate to pay attention to the needs of children so that they can be the best when learning. And not only material support, but students also really need moral support from their parents to increase their willingness to learn. So with this article, hopefully, it can be a reference for readers and also become a replica in the real world.

\section{Acknowledgement}

The authors would like to express their sincere gratitude to the members of Unilak-Research Advancement for Intellectual and Scientific Empowerment (U-RAISE) Academy who contribute in the discussion and consultation process of this paper.

\section{References}

Adeyemi, D. A., \& Kalane, M. S. (2011). English in Botswana junior secondary curriculum. International Journal of Educational Sciences, 3(2), 119-127.

Bamisaye, E. T. O. (2006). The English Language in Nigeria.

Booij, G. E. (2013). Morphology in construction grammar. In The Oxford handbook of construction grammar.

Currie, H. (1980). On the Proposal of Sociolinguistics as a Discipline of Research. Language in Society, 9(3), 407-411.

Currie, H. C. (1952). A projection of sociolinguistics: The relationship of speech to social status. Southern Speech Journal 18:28-37.

Littlewood, W., \& William, L. (1984). Foreign and second language learning: Language acquisition research and its implications for the classroom. Cambridge University Press.

Matsuoka, R., \& Smith, I. (2008). Age effects in second language acquisition: Overview. $J$ Nurs Studies NCNJ, 7(1), 33-40.

Melville, K. (2006). Big gender differences in language learning. Georgetown University Medical Center Recuperado de internet el, 18.

Ofodu, G. O. (2009). Comparative effects of two cooperative instructional methods on reading performance of secondary school students in Ekiti State, Nigeria (Doctoral dissertation, University of Ilorin).

Ofodu, G. O., \& Adeniyi, F. A. (2008). Impact of personality and environmental variables on learners' reading abilities. Journal of Educational Foundations and Management, 6(1), 195-201.

Onovughe, O. G. (2012). Sociolinguistics Inputs and English as Second Language Classrooms. English Language Teaching, 5(8), 157-163.
Sari, R., Putri, S. E., Herdi, H., \& Hamuddin, B. (2018). Bridging critical discourse analysis in media discourse studies. Indonesian EFL Journal, 4(2), 8089. 